\title{
Biologia de ninfas e adultos do percevejo-verde em estruturas reprodutivas de algodoeiro
}

\author{
Rosalia Azambuja( ${ }^{(1)}$, Paulo Eduardo Degrande ${ }^{(1)}$, Fabricio Fagundes Pereira(1) e Patrik Luiz Pastori(2)
}

\begin{abstract}
(1) Universidade Federal da Grande Dourados, Faculdade de Ciências Biológicas e Ambientais, Rodovia Dourados/ltahum, Km 12, Caixa Postal 322, CEP 79804-970 Dourados, MS, Brasil. E-mail: july_azambuja@yahoo.com.br, paulodegrande@ufgd.edu.br, fabriciofagundes@ufgd.edu.br (2)Universidade Federal do Ceará, Departamento de Fitotecnia, Avenida Mister Hull, № 2.977, Bloco 805, Campus do Pici, CEP 60356-000 Fortaleza, CE, Brasil. E-mail: plpastori@ufc.br
\end{abstract}

Resumo - O objetivo deste trabalho foi determinar a biologia de ninfas e adultos do percevejo-verde em estruturas reprodutivas do algodoeiro. Os alimentos testados foram: dieta padrão, contendo vagem de feijão, amendoim cru e frutos de ligustro; vagem verde de soja; semente de soja; botão floral de algodoeiro; e maçãs e sementes de algodoeiro. Foram avaliados os parâmetros biológicos: período de desenvolvimento e sobrevivência ninfal; longevidade de fêmeas e machos; percentagem de fêmeas em oviposição; períodos de pré-oviposição e oviposição; número total de ovos por fêmea; e viabilidade dos ovos. Ninfas alimentadas com estruturas reprodutivas do algodoeiro morreram no segundo ou no terceiro ínstar. Adultos alimentados com botão floral e semente de algodoeiro não se reproduzem; porém, há reprodução quando adultos os de percevejo-verde são alimentados com maçã de algodoeiro, o que indica a capacidade de adaptação da espécie na fase reprodutiva do algodoeiro.

Termos para indexação: Gossypium hirsutum, Nezara viridula, ecologia nutricional, hospedeiro alternativo.

\section{Biology of nymphs and adults of green stink bug in cotton reproductive structures}

\begin{abstract}
The objective of this work was to evaluate the biology of nymphs and adults of the green stink bug in cotton reproductive structures. The tested foods were: standard diet, containing green-bean pods, raw peanuts, and privet fruits; green soybean pods; soybean seed; cotton floral buds; and cotton bolls and seeds. The biological parameters evaluated were: nymphal developmental stage and survival; longevity of females and males; percentage of females in oviposition; pre-oviposition and oviposition periods; total number of eggs per female; and viability of eggs. Nymphs fed on cotton reproductive structures died in the second or third instar. Adults fed with cotton floral bud and seed do not reproduce; however, reproduction occurs when green stink bug adults are fed cotton bolls, indicating the adaptability capacity of the species in the reproductive stage of cotton.
\end{abstract}

Index terms: Gossypium hirsutum, Nezara viridula, nutritional ecology, alternative host.

\section{Introdução}

O percevejo-verde [Nezara viridula (L.) (Hemiptera: Pentatomidae)] é um inseto fitófago de distribuição mundial e elevada polifagia, que se alimenta de grande variedade de plantas silvestres e cultivadas (González et al., 2011; Musolin, 2012). Entre as plantas cultivadas, a soja (Glycine max L.) é o hospedeiro preferencial de N. viridula (Musolin, 2012; Souza et al., 2013). No campo, principalmente após a colheita da soja, o percevejo $N$. viridula se dispersa para plantas hospedeiras alternativas, em busca de abrigo e alimento (Panizzi, 2000). Essa dispersão é uma estratégia de sobrevivência e reprodução, durante o período em que o hospedeiro preferencial não está disponível (Panizzi, 1997).

O algodoeiro (Gossypium hirsutum L.) foi relatado como um novo hospedeiro alternativo para N. viridula, no Cerrado Brasileiro (Soria et al., 2010). A dispersão de $N$. viridula da soja para o algodoeiro também foi relatada nos Estados Unidos (Bundy \& McPherson, 2000; Reay-Jones et al., 2009). Essa dispersão, bem como o aumento da incidência de percevejos pentatomídeos na cultura do algodão, resulta, principalmente, da combinação de programas de erradicação do bicudo-do-algodoeiro, Anthonomus grandis (Boh.) (Coleoptera: Curculionidae), e da liberação comercial de variedades de algodão $B t$ que

Pesq. agropec. bras., Brasília, v.49, n.6, p.416-421, jun. 2014

DOI: 10.1590/S0100-204X2014000600002 
reduziram as aplicações de inseticidas na cultura. Esses fatores promoveram alterações nas técnicas de manejo de pragas na cultura; e essas mudanças, juntamente com a proximidade de áreas cultivadas com soja e outras plantas que hospedam a praga, contribuíram para que os percevejos ganhassem destaque como praga do algodoeiro (Reay-Jones et al., 2009).

No algodoeiro, $N$. viridula pode causar queda de maçãs jovens, manchas nas fibras por puncturas e, também, apodrecimento de maçãs pela transmissão de patógenos. Esses danos reduzem a quantidade do algodão em caroço, a produção de fibras e sementes, bem como a qualidade da pluma (Willrich et al., 2004; Reay-Jones et al., 2009).

O controle químico dessa praga com inseticidas de amplo espectro, não seletivos e comparativamente mais tóxicos, tem sido o método mais utilizado pelos produtores de algodão (Soria et al., 2010). Geralmente, a tomada de decisão de controle não leva em consideração o conhecimento básico da biologia do inseto na planta hospedeira, conforme o Manejo Integrado de Pragas (Santos et al., 2005). Não há relatos na literatura dos efeitos de estruturas reprodutivas do algodoeiro na biologia de $N$. viridula .

O objetivo deste trabalho foi determinar a biologia de ninfas e adultos de percevejo-verde em estruturas reprodutivas do algodoeiro.

\section{Material e Métodos}

Os experimentos foram realizados no Laboratório de Entomologia Aplicada da Faculdade de Ciências Agrárias da Universidade Federal da Grande Dourados (UFGD), no Município de Dourados, MS.

A criação de $N$. viridula foi estabelecida a partir de indivíduos coletados em lavoura de soja da área experimental da UFGD. Os insetos foram mantidos em recipientes de plástico $(19 \times 22 \times 10 \mathrm{~cm})$, forrados com papel filtro seco, e alimentados com vagens de feijão (Phaseolus vulgaris L.), grãos de soja, amendoim cru (Arachis hypogaea L.) e frutos de ligustro (Ligustrum lucidum W.T. Aiton), de acordo com Chocorosqui \& Panizzi (2008) e Depieri \& Panizzi (2011). Para permitir a aeração, as tampas dos recipientes de plástico foram recortadas no centro, e a abertura $(1,5 \times 1,5 \mathrm{~cm})$ foi coberta com tecido tipo organza. As gaiolas e o alimento foram trocados duas vezes por semana (Silva et al., 2008). A criação e os estudos de biologia foram realizados em sala climatizada a $25 \pm 1^{\circ} \mathrm{C}$, com umidade relativa do ar de $60 \pm 10 \%$ e fotofase de 14 horas (Fortes \& Cônsoli, 2011).

Massas de ovos obtidas da criação de manutenção foram acondicionadas em placas de Petri $(9 \mathrm{~cm}$ de diâmetro) forradas com papel filtro umedecido. Após a eclosão, as ninfas permaneceram agrupadas até a primeira ecdise, uma vez que não se alimentam no primeiro ínstar (Chocorosqui \& Panizzi, 2008).

As ninfas de segundo ínstar foram individualizadas em 240 potes de plástico $(250 \mathrm{~mL})$, forrados com papel de filtro seco, nos quais era ofertado o alimento a ser testado. Os alimentos avaliados foram: dieta padrão, composta por vagem de feijão + grão de amendoim cru + frutos de ligustro (Depieri \& Panizzi, 2011); vagem de soja 'BMX Potência', coletada entre os estádios R5 e R6; semente de soja madura 'BMX Potência', previamente embebida em água destilada por 24 horas; botão floral de algodoeiro 'DP Acala 90', com $0,5 \pm 0,1 \mathrm{~cm}$ contendo as brácteas; maçã de algodoeiro 'DP Acala 90', com 2,0 $\pm 0,5 \mathrm{~cm}$ de diâmetro contendo as brácteas; e semente de algodoeiro 'DP Acala 90', previamente embebida em água destilada por 24 horas. $\mathrm{O}$ botão floral e a maçã de algodoeiro foram previamente colocados em tubo Eppendorf contendo água destilada, para manter a turgidez das estruturas vegetais. $\mathrm{O}$ suprimento de água às ninfas foi feito por meio de algodão umedecido, colocado em tubo Eppendorf. Os alimentos foram trocados a cada dois dias (Silva et al., 2008).

Observações diárias foram realizadas para registro da mudança de ínstar e da mortalidade. No dia da emergência dos adultos, estes foram separados por sexo e pesados em balança eletrônica. Os parâmetros biológicos avaliados foram: período de desenvolvimento ninfal do segundo ao quinto ínstar; e duração e percentagem de sobrevivência em cada ínstar. Utilizou-se o delineamento experimental inteiramente casualizado, com seis tratamentos (alimentos) e 40 repetições.

A avaliação da biologia dos adultos foi feita apenas com adultos provenientes de ninfas alimentadas com a dieta padrão. Isso porque as ninfas alimentadas com as estruturas reprodutivas do algodoeiro não se desenvolveram completamente. Seguindo a mesma metodologia adotada para as ninfas, 72 casais foram individualizados em potes de plástico $(250 \mathrm{~mL})$, forrados com papel de filtro seco. Os tratamentos 
avaliados foram os mesmos utilizados no teste com as ninfas. A água foi oferecida em algodão umedecido.

Foram avaliados a longevidade de machos e fêmeas, a percentagem de fêmeas em oviposição, o período de pré-oviposição e oviposição, e o número total de ovos por fêmea (Chocorosqui \& Panizzi, 2008). Para a determinação da viabilidade dos ovos (número de ovos eclodidos/total de ovos), eles foram mantidos em placas de Petri forradas com papel filtro umedecido e verificados diariamente (Chocorosqui \& Panizzi, 2008). Utilizou-se o delineamento experimental inteiramente casualizado, com seis tratamentos (alimentos) e 12 repetições, e cada unidade experimental foi composta por um casal de $N$. viridula.

Os dados foram submetidos à análise de variância, e as médias foram comparadas pelo teste de Tukey, a 5\% de probabilidade (Chocorosqui \& Panizzi, 2008; Fortes \& Cônsoli, 2011; Silva et al., 2011). Para as análises, os dados de longevidade de machos e fêmeas e o número total de ovos por fêmea foram transformados para raiz $(\mathrm{x}+0,5)$, tendo-se apresentado, no entanto, os dados originais. Esses procedimentos foram realizados com uso do programa estatístico Sisvar 5.1 (Ferreira, 2008).

\section{Resultados e Discussão}

Em maçã e semente de algodoeiro, apenas 5,0 e 2,5\% das ninfas de $N$. viridula completaram o segundo ínstar, respectivamente (Tabela 1). A mortalidade de ninfas de terceiro ínstar alimentadas com maçã e semente de algodoeiro foi de $100 \%$. Ninfas alimentadas com botão floral de algodoeiro não conseguiram completar o segundo ínstar.
O segundo ínstar de ninfas alimentadas com maçã de algodoeiro apresentou maior duração do que quando alimentadas com dieta padrão e vagem de soja. Esse resultado, aliado às mortalidades relatadas, indica inadequação nutricional dessas estruturas para as ninfas de $N$. viridula, ou uma possível falta de reconhecimento destas fontes de alimento por elas. Segundo Panizzi (2000), as características físicas e químicas e a qualidade nutricional dos alimentos são responsáveis por repostas diferenciais dos insetos, e podem causar aumento no período de desenvolvimento biológico dos imaturos ou elevada mortalidade.

A mortalidade de ninfas alimentadas com as diferentes estruturas reprodutivas do algodoeiro indica que esta planta não é um hospedeiro alternativo adequado para o desenvolvimento ninfal de $N$. viridula. Portanto, o algodoeiro estaria servindo apenas como abrigo, nos agroecossistemas, por ocasião do final do ciclo da soja. Plantas hospedeiras alternativas normalmente são utilizadas pelos percevejos como fonte de alimento e abrigo na falta do hospedeiro preferencial, mas, no geral, apresentam baixa qualidade nutricional e não permitem completo desenvolvimento ninfal, o que as tornam uma opção para os adultos se manterem vivos (Panizzi, 2000).

A dieta padrão, a vagem e a semente de soja permitiram que as ninfas atingissem a fase adulta (Tabela 1). O período de desenvolvimento ninfal total do segundo ao quinto ínstar e a duração média de cada ínstar de $N$. viridula foram menores com a dieta padrão e a vagem de soja. A vagem verde tem sido o alimento preferencial de $N$. viridula em lavouras de soja e, quando utilizada nos estádios R6, R7 e R8, permite o desenvolvimento completo do inseto (Panizzi, 2000),

Tabela 1. Duração e sobrevivência (SV) do percevejo-verde Nezara viridula, quando alimentado com diferentes dietas ${ }^{(1)}$.

\begin{tabular}{|c|c|c|c|c|c|c|c|c|c|c|}
\hline \multirow[t]{2}{*}{ Dieta } & \multicolumn{2}{|c|}{$2^{\circ}$ ínstar } & \multicolumn{2}{|c|}{$3^{\circ}$ ínstar } & \multicolumn{2}{|c|}{$4^{\circ}$ ínstar } & \multicolumn{2}{|c|}{$5^{\circ}$ ínstar } & \multicolumn{2}{|c|}{$2^{\circ}$ instar-adulto } \\
\hline & $\begin{array}{c}\text { Duração } \\
\text { (dias) }\end{array}$ & $\begin{array}{l}\text { SV } \\
(\%)\end{array}$ & $\begin{array}{c}\text { Duração } \\
\text { (dias) }\end{array}$ & $\begin{array}{l}\text { SV } \\
(\%)\end{array}$ & $\begin{array}{c}\text { Duração } \\
\text { (dias) }\end{array}$ & $\begin{array}{l}\text { SV } \\
(\%)\end{array}$ & $\begin{array}{c}\text { Duração } \\
\text { (dias) }\end{array}$ & $\begin{array}{l}\text { SV } \\
(\%)\end{array}$ & $\begin{array}{c}\text { Duração } \\
\text { (dias) }\end{array}$ & $\begin{array}{l}\text { SV } \\
(\%)\end{array}$ \\
\hline Dieta padrão & $6,93 \pm 0,27 a$ & 82,5 & $6,07 \pm 0,27 a$ & 84,8 & $6,74 \pm 0,32 \mathrm{a}$ & 96,4 & $9,33 \pm 0,33 a$ & 96,2 & $28,88 \pm 0,76 \mathrm{a}$ & 65,0 \\
\hline Vagem de soja & $6,50 \pm 0,20 \mathrm{a}$ & 70,0 & $6,60 \pm 0,40 \mathrm{a}$ & 71,4 & $7,46 \pm 0,33 \mathrm{a}$ & 75,0 & $11,00 \pm 0,96 \mathrm{a}$ & 73,3 & $32,09 \pm 1,35 \mathrm{a}$ & 27,5 \\
\hline Semente de soja & $10,35 \pm 0,75 b$ & 35,0 & $9,85 \pm 0,50 \mathrm{~b}$ & 50,0 & $9,71 \pm 1,40 \mathrm{~b}$ & 50,0 & $14,40 \pm 1,43 b$ & 71,4 & $42,40 \pm 2,42 b$ & 12,5 \\
\hline Botão floral de algodoeiro & - & 0,0 & - & 0,0 & - & 0,0 & - & 0,0 & - & 0,0 \\
\hline Maçã de algodoeiro & $10,00 \pm 0,00 \mathrm{~b}$ & 5,0 & - & 0,0 & - & 0,0 & - & 0,0 & - & 0,0 \\
\hline Semente de algodoeiro & $16^{*}$ & 2,5 & - & 0,0 & - & 0,0 & - & 0,0 & - & 0,0 \\
\hline
\end{tabular}

${ }^{(1)}$ Médias \pm erro-padrão seguidas de letras iguais, nas colunas, não diferem pelo teste de Tukey, a 5\% de probabilidade. *Dados excluídos das análises estatísticas, pois houve sobrevivência de apenas um indivíduo. Número inicial de ninfas $=40$. Temperatura de $25 \pm 1{ }^{\circ} \mathrm{C}$, umidade relativa de $60 \pm 10 \%$ e fotofase de 14 horas. 
o que está de acordo com o observado no presente trabalho.

O prolongamento do período ninfal e a baixa percentagem de sobrevivência de ninfas alimentadas com sementes de soja maduras também podem ser decorrentes da falta de reconhecimento desta fonte de alimento pelas ninfas, uma vez que este percevejo, no campo, alimenta-se das vagens verdes de soja (Depieri \& Panizzi, 2011). Em criações de laboratório, as sementes maduras de soja são indicadas para alimentação de ninfas apenas a partir do terceiro ínstar, em razão da fragilidade do aparelho bucal dos insetos imaturos (Panizzi \& Silva, 2009). Molina \& Trumper (2012), ao avaliar ninfas alimentadas com vagens de soja no estádio fenológico R8 (no qual as vagens estão secas), também observaram baixa sobrevivência ninfal, já que, nesse estádio, os tecidos estão mais resistentes aos danos mecânicos.

A longevidade de fêmeas e de machos adultos de $N$. viridula foi menor quando alimentados com botão floral e semente de algodoeiro (Tabela 2). Esse

Tabela 2. Longevidade de fêmeas e machos adultos do percevejo-verde Nezara viridula, alimentados com diferentes dietas ${ }^{(1)}$.

\begin{tabular}{lcc}
\hline Dieta & Fêmeas & Machos \\
\hline Dieta padrão & $36,33 \pm 4,74 \mathrm{a}$ & $37,75 \pm 4,61 \mathrm{a}$ \\
Vagem de soja & $33,91 \pm 3,68 \mathrm{a}$ & $39,41 \pm 4,19 \mathrm{a}$ \\
Semente de soja & $34,16 \pm 2,98 \mathrm{a}$ & $30,50 \pm 1,48 \mathrm{a}$ \\
Botão floral de algodoeiro & $15,41 \pm 1,94 \mathrm{~b}$ & $13,25 \pm 0,95 \mathrm{~b}$ \\
Maçã de algodoeiro & $39,41 \pm 4,91 \mathrm{a}$ & $37,58 \pm 3,49 \mathrm{a}$ \\
Semente de algodoeiro & $17,33 \pm 2,19 \mathrm{~b}$ & $19,58 \pm 1,82 \mathrm{~b}$ \\
\hline
\end{tabular}

${ }^{(1)}$ Médias \pm erro-padrão seguidas de letras iguais, nas colunas, não diferem pelo teste de Tukey, a $5 \%$ de probabilidade. Número de casais, 12. Temperatura de $25 \pm 1^{\circ} \mathrm{C}$, umidade relativa de $60 \pm 10 \%$ e fotofase de 14 horas. resultado provavelmente está relacionado à baixa qualidade nutricional desses alimentos ou à presença de compostos deterrentes, que reduzem a alimentação, a digestibilidade e a assimilação dos nutrientes pelos percevejos (Awmack \& Leather, 2002).

Quanto aos parâmetros reprodutivos, foram observadas diferenças significativas entre os tratamentos, sendo que fêmeas alimentadas com botão floral e semente de algodoeiro não ovipositaram (Tabela 3). A reprodução é um processo biológico que está diretamente relacionado à qualidade nutricional da planta hospedeira, pois ocorre apenas quando o alimento fornece nutrientes que permitam a produção de ovos, a nutrição da progênie e a sobrevivência da fêmea (Awmack \& Leather, 2002; Panizzi \& Silva, 2009). Fêmeas expostas a plantas com qualidade nutricional insatisfatória podem reabsorver ovos ou embriões e utilizar os nutrientes para aumentar sua longevidade (Awmack \& Leather, 2002). Contudo, isso parece não ter ocorrido no presente trabalho, uma vez que a longevidade das fêmeas foi reduzida quando botões florais e sementes de algodoeiro foram fornecidos como alimento (Tabela 2).

A duração do período de pré-oviposição foi maior para as fêmeas alimentadas com maçã de algodoeiro e semente de soja e menor para as alimentadas com dieta padrão (Tabela 3). De acordo com Parra et al. (2009), o prolongamento do período de pré-oviposição é uma estratégia reprodutiva dos insetos, que permite acumular energia e nutrientes necessários para desencadear os processos reprodutivos de ovogênese e oviposição. O período de oviposição das fêmeas e a percentagem de viabilidade dos ovos não foram afetados pelos tratamentos. No entanto, o número total de ovos por fêmea foi maior para as alimentadas com dieta padrão, e semelhante para as alimentadas com

Tabela 3. Duração dos períodos de pré-oviposição e oviposição, número médio do total de ovos por fêmea, viabilidade média de ovos e percentual médio de fêmeas em oviposição do percevejo-verde Nezara viridula, alimentado com diferentes dietas ${ }^{(1)}$.

\begin{tabular}{|c|c|c|c|c|c|}
\hline \multirow[t]{2}{*}{ Dieta } & \multicolumn{2}{|c|}{ Período (dias) } & \multirow{2}{*}{$\begin{array}{l}\text { Número total de ovos } \\
\text { por fêmea }\end{array}$} & \multirow{2}{*}{$\begin{array}{c}\text { Viabilidade de ovos } \\
(\%)\end{array}$} & \multirow{2}{*}{$\begin{array}{c}\text { Fêmeas em oviposição } \\
(\%)\end{array}$} \\
\hline & Pré-oviposição & Oviposição & & & \\
\hline Dieta padrão & $13,10 \pm 1,28 \mathrm{a}$ & $29,50 \pm 4,37 \mathrm{a}$ & $291,30 \pm 59,4 a$ & $52,50 \pm 12,26 \mathrm{a}$ & $83,0(10)$ \\
\hline Vagem de soja & $19,66 \pm 1,11 \mathrm{~b}$ & $20,33 \pm 4,75 a$ & $77,00 \pm 9,50 \mathrm{~b}$ & $45,66 \pm 20,60 \mathrm{a}$ & $50,0(6)$ \\
\hline Semente de soja & $27,50 \pm 0,64 \mathrm{c}$ & $10,75 \pm 6,25 \mathrm{a}$ & $49,75 \pm 10,77 b$ & $40,50 \pm 21,69 \mathrm{a}$ & $33,0(4)$ \\
\hline Botão floral de algodoeiro & - & - & - & - & $0,0(0)$ \\
\hline Maçã de algodoeiro & $30,25 \pm 1,44 \mathrm{c}$ & $16,87 \pm 3,29 \mathrm{a}$ & $46,75 \pm 4,26 \mathrm{~b}$ & $40,25 \pm 15,68 \mathrm{a}$ & $66,0(8)$ \\
\hline Semente de algodoeiro & - & - & - & - & $0,0(0)$ \\
\hline
\end{tabular}

${ }^{(1)}$ Médias \pm erro-padrão seguidas de letras iguais, nas colunas, não diferem pelo teste de Tukey, a $5 \%$ de probabilidade. Número inicial de casais, 12 ; número de fêmeas entre parênteses. Temperatura de $25 \pm 1^{\circ} \mathrm{C}$, umidade relativa de $60 \pm 10 \%$ e fotofase de 14 horas. 
vagem e semente de soja e com maçã de algodoeiro. Apesar do prolongamento do período de pré-oviposição das fêmeas alimentadas com maçã de algodoeiro e da redução no número de ovos por fêmea, em comparação à dieta padrão, constatou-se que a maçã de algodoeiro é um alimento nutricionalmente adequado para $\mathrm{o}$ desenvolvimento reprodutivo de adultos de $N$. viridula. Portanto, em condições de campo, a colheita da soja, em áreas próximas a algodoais que estejam no estádio fenológico de produção de maças, pode favorecer a dispersão e a reprodução dos percevejos.

\section{Conclusões}

1. Ninfas de Nezara viridula não se desenvolvem quando alimentadas com botão floral, maçã e semente de algodoeiro.

2. Adultos de $N$. viridula se reproduzem quando alimentados com maçã de algodoeiro.

\section{Agradecimentos}

Ao Conselho Nacional de Desenvolvimento Científico e Tecnológico (CNPq), pela concessão de bolsa (Processo 149968/2010-8).

\section{Referências}

AWMACK, C.S.; LEATHER, S.R. Host plant quality and fecundity in herbivorous insects. Annual Review of Entomology, v.47, p.817-844, 2002. DOI: 10.1146/annurev. ento.47.091201.145300.

BUNDY, C.S.; MCPHERSON, R.M. Dynamics and seasonal abundance of stink bugs (Heteroptera: Pentatomidae) in a cotton-soybean ecosystem. Journal of Economic Entomology, v.93, p.697-706, 2000. DOI: 10.1603/0022-0493-93.3.697.

CHOCOROSQUI, V.R.; PANIZZI, A.R. Nymph and adult biology of Dichelops melacanthus (Dallas) (Heteroptera: Pentatomidae) feeding on cultivated and non-cultivated host plants. Neotropical Entomology, v.37, p.353-360, 2008. DOI: 10.1590/ S1519-566X2008000400001.

DEPIERI, R.A.; PANIZZI, A.R. Duration of feeding and superficial and in-depth damage to soybean seed by selected species of stink bugs (Heteroptera: Pentatomidae). Neotropical Entomology, v.40, p.197-203, 2011. DOI: 10.1590/S1519-566X2011000200007.

FERREIRA, D.F. SISVAR: um programa para análises e ensino de estatística. Revista Symposium, v.6, p.36-41, 2008.

FORTES, P.; CÔNSOLI, F.L. Are there costs in the repeated mating activities of female Southern stink bugs Nezara viridula? Physiological Entomology, v.36, p.215-219, 2011. DOI: 10.1111/j. 1365-3032.2011.00786.x.
GONZÁlEZ, J.W.; GUTIÉRREZ, M.M.; FERRERO, A.A. Repellency assays with plant extracts and essential oils from Schinus molle var. areira (L) (Anacardiaceae) and DEET against Nezara viridula L. (Hemiptera: Pentatomidae). BioAssay, v.6, p.1-4, 2011

MOLINA, G.A.R.; TRUMPER, E.V. Selection of soybean pods by the stink bugs, Nezara viridula and Piezodorus guildinii. Journal of Insect Science, v.12, p.1-16, 2012. DOI: 10.1673/031.012.10401.

MUSOLIN, D.L. Surviving winter: diapause syndrome in the southern green stink bug Nezara viridula in the laboratory, in the field, and under climate change conditions. Physiological Entomology, v.37, p.309-322, 2012. DOI: 10.1111/j.1365-3032.2 012.00846.x.

PANIZZI, A.R. Suboptimal nutrition and feeding behavior of hemipterans on less preferred plant food sources. Anais da Sociedade Entomológica do Brasil, v.29, p.1-12, 2000. DOI: 10.1590/S0301-80592000000100001.

PANIZZI, A.R. Wild hosts of Pentatomids: ecological significance and role in their pest status on crops. Annual Review of Entomology, v.42, p.99-122, 1997. DOI: 10.1146/annurev. ento.42.1.99.

PANIZZI, A.R.; SILVA, F.A.C. Insetos sugadores de sementes (Heteroptera). In: PANIZZI, A.R.; PARRA, J.R.P. (Ed.). Bioecologia e nutrição de insetos: base para o manejo integrado de pragas. Brasília: Embrapa Informação Tecnológica; Londrina: Embrapa Soja, 2009. p.465-522.

PARRA, J.R.P.; PANIZZI, A.R.; HADDAD, M.L. Índices nutricionais para medir consumo e utilização de alimentos por insetos. In: PANIZZI, A.R.; PARRA, J.R.R. (Ed.). Bioecologia e nutrição de insetos: base para o manejo integrado de pragas. Brasília: Embrapa Informação Tecnológica; Londrina: Embrapa Soja, 2009. p.37-90.

REAY-JONES, F.P.F.; GREENE, J.K.; TOEWS, M.D.; REEVES, R.B. Sampling stink bugs (Hemiptera: Pentatomidae) for population estimation and pest management in southeastern cotton production. Journal of Economic Entomology, v.102, p.2360-2370, 2009. DOI: $10.1603 / 029.102 .0643$.

SANTOS, K.B. dos; MENEGUM, A.M.; NEVES, P.M.O.J. Biology and consumption of Spodoptera eridania (Cramer) (Lepidoptera: Noctuidae) in different hosts. Neotropical Entomology, v.34, p.903-910, 2005. DOI: 10.1590/S1519-566X2005000600005.

SILVA, C.C.; LAUMANN, R.A.; BLASSIOLI, M.C.; PAREJA, M.; BORGES, M. Euschistus heros mass rearing technique for the multiplication of Telenomus podisi. Pesquisa Agropecuária Brasileira, v.43, p.575-580, 2008. DOI: 10.1590/ S0100-204X2008000500004.

SILVA, F.A.C.; CALIZOTTI, G.S.; PANIZZI, A.R. Survivorship and egg production of phytophagous pentatomids in laboratory rearing. Neotropical Entomology, v.40, p.35-38, 2011. DOI: 10.1590/S1519-566X2011000100005.

SORIA, M.F.; DEGRANDE, P.D.; PANIZZI, A.R. Maior incidência de percevejos fitófagos na cultura do algodão. Cultivar: Grandes Culturas, v.131, p.18-20, 2010. 
SOUZA, E. de S.; BALDIN, E.L.L.; SILVA, J.P.G.F. da; LOURENÇÃO, A.L. Feeding preference of Nezara viridula (Hemiptera: Pentatomidae) and attractiveness of soybean genotypes. Chilean Journal of Agricultural Research, v.73, p.351-357, 2013. DOI: 10.4067/S0718-58392013000400004.
WILLRICH, M.M.; LEONARD, B.R.; PADGETT, G.B. Influence of southern green stink bug, Nezara viridula L., on late-season yield losses in cotton, Gossypium hirsutum L. Environmental Entomology, v.33, p.1095-1101, 2004. DOI: 10.1603/0046-225X-33.4.1095.

Recebido em 15 de fevereiro de 2014 e aprovado em 23 de maio de 2014 